\title{
Comparative Pertussis Antibody Response of Nigerian Children to Diphtheria, Pertussis, Tetanus (DPT) and Pentavalent Vaccines
}

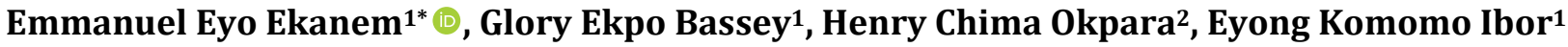 \\ ${ }^{1}$ Dept. of Paediatrics, University of Calabar and University of Calabar Teaching Hospital, Calabar, Nigeria \\ ${ }^{2}$ Dept. of Chemical Pathology, University of Calabar and University of Calabar Teaching Hospital, Calabar, Nigeria \\ Email: * profekanem@gmail.com
}

How to cite this paper: Ekanem, E.E., Bassey, G.E., Okpara, H.C. and Ibor, E.K. (2020) Comparative Pertussis Antibody Response of Nigerian Children to Diphtheria, Pertussis, Tetanus (DPT) and Pentavalent Vaccines. World Journal of Vaccines, 10 , 43-53.

https://doi.org/10.4236/wjv.2020.103004

Received: June 6, 2020

Accepted: August 28, 2020

Published: August 31, 2020

Copyright $\odot 2020$ by author(s) and Scientific Research Publishing Inc. This work is licensed under the Creative Commons Attribution International License (CC BY 4.0).

http://creativecommons.org/licenses/by/4.0/

(c) (i) Open Access

\begin{abstract}
Background: In Nigeria Pentavalent vaccine had replaced Diphtheria-PertussisTetanus [DPT] vaccine in the prevention of pertussis since 2012. Aims and Objectives: The aim of this study was to compare the anti-pertussis immunoglobin $\mathrm{G}$ (IgG) response of children who received DPT with those who received the pentavalent vaccine. Subjects and Methods: This study was carried out in Akpabuyo LGA of Cross River State from April to June 2016. It was a cross-sectional survey of anti-pertussis IgG levels in children aged 6 months to 5 years who received DPT and those who received pentavalent vaccine. IgG antibody levels were determined using enzyme-linked immunosorbent assay. The protective level was set at $>11$ DU according to manufacturer's cut off point. Results: Seventy eight out of 230 children [33.9\%] who had received DPT had protective levels of anti-pertussis IgG compared to 74 out of 192 children [38.5\%] who had received pentavalent vaccine. The difference was not statistically significant $[p=0.61]$. The median IgG antibody level in those who received DPT was $8.0 \mathrm{DU}$ (interquartile range (IQR) 4.0 13.0) compared with 9.0 DU (IQR) 4.0 - 15.0 in those who received pentavalent vaccine $[p=0.18]$. No single factor investigated predicted the development of protective levels of antibody in the multivariate analysis. Conclusion/Recommendation: There was no difference in the antipertussis antibody response between DPT and pentavalent vaccines recipients. Further study is needed to elucidate factors that could be responsible for low anti-pertussis antibody response in this population.
\end{abstract}

\section{Keywords}

Anti-Pertussis Immunoglobulin G, Diphtheria-Pertussis-Tetanus, Pentavalent Vaccine, Comparative 


\section{Introduction}

Bordetella pertussis is a gram-negative bacillus that causes the highly contagious disease pertussis or whooping cough [1]. It is responsible for a worldwide estimated 50 million illness cases (90\% of which are in developing countries) and 400,000 deaths each year [1].

B. pertussis seems to be re-emerging [2] [3] and several explanations have been put forward for the resurgence of $B$. pertussis infection in vaccinated populations. These include improved disease surveillance, changes in case definition, better diagnostic techniques [4], demographic changes, waning vaccine-induced immunity, changes in vaccine quality and/or vaccine coverage, and a decrease in the vaccine efficacy due to antigenic differences between circulating isolates and vaccinal strains [5]. Prevention of pertussis is basically by vaccination and immunization. It is important to note that vaccination does not always result in immunization. This means that one received the vaccine but protection is not achieved. In Nigeria, the three doses of the primary vaccination for pertussis in the National Programme on Immunization (NPI) is given at 6,10 and 14 weeks [6]. The NPI since its inception was using the Diphtheria, Pertussis and Tetanus (DPT) vaccine which contained the whole cell pertussis until 2012 when the pentavalent vaccine containing DPT, hepatitis B and Haemophilus influenza was introduced [7].

Antibody response in children may vary depending on the vaccination schedule and the product used [8]. Baker et al. [9] reported that there is a wide range of antibody response to $B$. pertussis antigens after immunization with various whole cell pertussis vaccines. The administration of other vaccine antigens concurrently may affect these responses [9]. To the best of our knowledge no study has been done in our locale to compare the anti-pertussis antibody response of children to DPT and pentavalent vaccines.

The aim of this study was to compare the anti-pertussis antibody levels in $\mathrm{Ni}$ gerian children aged six to sixty months who had received plain DPT with those who had received the pentavalent vaccine and also to find possible predictors of variability, if any, including age and sex.

\section{Subjects and Methods}

\subsection{Study Location}

The study was carried out in Akpabuyo Local Government Area (LGA) of Cross River State from April to June 2016. Cross River state is in the South South geopolitical zone of Nigeria. Akpabuyo LGA is bounded by Akamkpa LGA in the North, Calabar Municipality in the West, Bakassi LGA in the East and the Cross River in the South. There are 10 wards with a total population of 313,097 [10] and under 5 population of 62,619 [10]. Immunization is usually given at the Primary Health Centers in this LGA.

\subsection{Sample Size Determination}

The prevalence rate of $50 \%$ was used in this study to derive the minimum sam- 
ple size of 422 children using the formula $N=z^{2} \times p \times(1-p) / d^{2}$. This was because the investigators were not aware of any previous study on this subject in Nigeria.

\subsection{Patient Recruitment and Selection Criteria}

This study was a cross-sectional descriptive study conducted in Akpabuyo LGA. Multistage sampling technique was used to recruit children aged 6 - 59 months who met the inclusion criteria. Immunization cards were used to identify those who had received three doses of DPT/pentavalent vaccine. Socio-demographic characteristic (age, gender, parent's educational level and occupation) were collected. The socioeconomic class of the participants was assessed using the method employed by Olusanya et al. [11]. This method combines scores of father's occupation (professionals: 1, middle class bureaucrats: 2, unskilled workers: 3 ); and mother's education (university education: 0 , secondary or below tertiary: 1 , primary or no formal education: 2) to classify the children into social classes I to V. The last date of DPT/pentavalent vaccine were noted and blood samples were then taken for determination of immunoglobulin G (IgG) levels. These children were put into two groups. The first group received plain DPT vaccine and the second group were those who received pentavalent vaccine.

\section{Ethical Issues}

Ethical clearance for this study was obtained from the Human Research Ethics Committees of the University of Calabar Teaching Hospital with letter reference number UCTH/HREC/33/245 dated $17^{\text {th }}$ March 2016 and Cross River State Government with letter reference number CRS/MH/CGS/E-H/018/Vol-II/117 dated $7^{\text {th }}$ January 2016. Permission was obtained from Akpabuyo Local Government Council and the village heads.

\section{Informed consent}

Parents or guardians of children in the selected villages were given a copy of the statement of the study to read following which they gave written consent. For those who were not able to read, the investigator explained the nature of the study to them. The screening form for eligibility was given to them to fill to identify those eligible for the study. There was no consequence for those who withdraw his/her child from the study.

\section{General clinical assessment of subjects}

For children that their parents gave consent, their bio-data including tribe, parent's occupation and education level and immunization history were obtained from the parent using a semi-structured questionnaire (Appendix I). Present illness and past medical history were assessed verbally. Immunization status was confirmed by visualizing the card. Patients without immunization cards were excluded from the study.

\section{Patient preparation, specimen collection and preservation}

The procedure for specimen collection was explained to the parents or guardians before venepuncture. $2 \mathrm{mls}$ of whole blood was collected from each eligible child into a plain bottle and allowed to clot. The samples were preserved in a 
cooler of ice packs and transported to the Paediatric side laboratory of University of Calabar Teaching Hospital (UCTH). The clotted sample was centrifuged at $3000 \mathrm{rpm}$ for 5 minutes. The serum was separated and transferred into storage tube and stored at $-20^{\circ} \mathrm{C}$ for a maximum of a week before batch analysis. Labeling was done with coded numbers to avoid mistakes.

\section{Laboratory evaluation}

The test was performed by GB and supervised by a Chemical Pathologist. The samples were tested for IgG antibody against Bordetella Pertussis using a commercially available ELISA test kit; Bordetella pertussis toxin IgG (DRG Instruments $\mathrm{GmbH}$, Germany) with LOT number 101G/K036-2 and expiration date of $31^{\text {st }}$ March 2017. Reagent preparation, assay procedures and evaluation of results for anti-pertussis antibodies were carried out according to manufacturer's instruction manual. To ensure analytical quality a Chemical Pathologist verified the results, by carrying out the ELISA testing on every $20^{\text {th }}$ subject's blood sample and cross checking with the negative and positive control sera that came with the test kit. The kit was stored and preserved in the refrigerator temperature of $2^{\circ} \mathrm{C}-4^{\circ} \mathrm{C}$ till completion of the study.

\section{Interpretation of results}

Results were evaluated according to manufacturer's classification and values of $<9 \mathrm{DU}, 9-11 \mathrm{DU}$ and $>11 \mathrm{DU}$ were taken as negative, borderline and positive respectively. Those that were positive were taken to be protected.

\section{Data analysis}

Data entry was into Microsoft Excel spreadsheet and later imported into SPSS for cleaning and analysis. The data obtained was analyzed using Statistical Package for Social Sciences (SPSS) version 25.0 (IBM, USA). Frequencies (and proportions) and means (standard deviation) or medians (interquartile range) were used to summarize data as appropriate. Median and standard deviation were used to summarize data. Inferential statistics with the use of Chi-square test (for qualitative data) and Mann-Whitney U test (for non-normally distributed quantitative variables) were used to test for association between bivariate at 5\% level of significance. Differences between median values of antibody levels after three doses of DPT between the age groups were compared using the Mann-Whitney $\mathrm{U}$ test. Univariable and multivariable linear regression analysis was performed to determine the predictors of antibody response in the two groups. A $p$-value of $<0.05$ was deemed statistically significant. A multivariable linear regression model was used to control for effect of possible confounders and identify independent factors that have effect on changes in serum anti-pertussis IgG levels. Factors with $p$-value of the Wald statistic $<0.05$ at the univariate level and those with biologic plausibility were introduced into the final multivariable model.

\section{Results}

Four hundred and twenty two infants and children were recruited into the study. Males constituted $220(52.13 \%)$ and females $202(47.87 \%)$ of the subjects (Table $1)$. 
Table 1. Socio-demographic characteristics of study participants.

\begin{tabular}{ccc}
\hline & Frequency $(N=\mathbf{4 2 2})$ & Percentage (100.0\%) \\
\hline Age group/months & 93 & 22.0 \\
$\leq 12$ & 95 & 22.5 \\
$13-24$ & 72 & 17.1 \\
$25-36$ & 162 & 38.4 \\
$>36$ & $30.04 \pm 16.88$ months & \\
Mean age \pm SD & & 52.1 \\
Sex & 220 & 47.9 \\
Male & 202 & \\
Female & & 10.43 \\
Social class & 44 & 20.88 \\
1 & 88 & 32.46 \\
11 & 137 & 20.62 \\
111 & 87 & 15.64 \\
IV & 66 & \\
V & &
\end{tabular}

Social class distribution was as follows: Class I ( $44 \%$ or $10.43 \%$ ); Class II ( $88 \%$ or $20.88 \%)$; Class III (137\% or $32.46 \%)$; Class IV (87\% or $20.62 \%)$ and Class V ( $66 \%$ or $15.64 \%)$. Their ages ranged from 6 to 59 months with a mean of $30.04 \pm$ 16.88 and median of 28 months (IQR: 14 - 44 months).

The mean age of those on DPT was $16.57 \pm 7.60$ [95\% CI $=15.59-17.57]$ months while the mean age for those who had Pentavalent vaccine was $46.17 \pm$ $8.89[95 \% \mathrm{CI}=44.91-47.44]$ months. $(\mathrm{t}=-36.85 ; p<0.001)$.

One hundred and eighteen of the 220 males had DPT while 112 of the $202 \mathrm{fe}-$ males had pentavalent vaccine $\left(\chi^{2}=0.14 ; p=0.71\right)$. There was no difference in the social classes of those who had DPT compared to those that had pentavalent vaccine $\left(\chi^{2}=2.10 ; p=0.72\right)$.

\section{IgG Levels}

The mean IgG level for the whole population was $8.97 \pm 5.50 \mathrm{DU}$ with a median of 8.0 DU (IQR: 4.0 - 14.0).

The mean for those that had DPT was $8.57 \pm 5.10 \mathrm{DU}$ with a median of 8.0 DU [IQR: 4.0 - $13.0 \mathrm{i} \mu / \mathrm{ml}$ ]. The range was 0 - $18 \mathrm{DU}$.

The range for those that had pentavalent vaccine was 0 - $21 \mathrm{DU}$, mean $9.44 \pm$ $5.93 \mathrm{DU}$, median 9.0 (IQR 4.0 - 15.0) DU. The difference was not significant (Mann-Whitney U test $p=0.18$ ).

Table 2 shows the distribution of antibody response among those who had DPT compared to those who had pentavalent vaccine.

Seventy-eight (33.9\%) (95\% CI: $27.82 \%-40.43 \%$ ) of those who had DPT had protective levels of antibody while 74 (38.5\%) (95\% CI: 31.62\% - 45.82\%) of those who had pentavalent vaccine had protective levels. The difference was not significant $(p=0.61)$. 
Table 2. IgG levels by vaccine type.

\begin{tabular}{|c|c|c|c|c|c|c|}
\hline \multicolumn{2}{|c|}{ Vaccine Type Range $(\mathrm{i} \mu / \mathrm{ml})$} & \multirow{2}{*}{$\begin{array}{c}\text { Median } \\
8.0\end{array}$} & \multirow{2}{*}{$\begin{array}{c}\mathrm{IQR}^{*} \\
4.0-13.0\end{array}$} & \multirow{2}{*}{$\begin{array}{l}\text { Low }(\mathrm{n} / \%) \\
92(40.0)\end{array}$} & \multirow{2}{*}{$\begin{array}{c}\text { Indeterminate } \\
(\mathrm{n} / \%)\end{array}$} & \multirow{2}{*}{$\begin{array}{c}\begin{array}{c}\text { Protective } \\
(\mathrm{n} / \%)^{\beta}\end{array} \\
78(33.9)\end{array}$} \\
\hline DPT & $0-18$ & & & & & \\
\hline Pentavalent & $0-21$ & 9.0 & $4.0-15.0$ & $71(37.0)$ & $47(24.5)$ & $74(38.5)$ \\
\hline
\end{tabular}

${ }^{*}$ Mann-Whitney $\mathrm{U}$ test $p$-value $=0.18,{ }^{\beta}$ Chi-Square test $p$-value $=0.61$.

At the univariate level, vaccine type, age, sex and social class did not affect vaccine response. Similarly, at the multivariate level, no single factor investigated predicted the development of protective levels of antibody.

\section{Discussion}

An earlier work in this population had examined the response of these children to DPT and pentavalent vaccines and noted low antibody levels in these children [12]. The purpose of the current work was to determine if there is any difference in their anti-pertussis antibody response between DPT and pentavalent vaccines.

With advent of various new vaccines for combating infectious diseases, promotion of combination vaccines seems essential for simplifying the increasing complexity of immunization program of any country. It is important to also note that the potency of the vaccine plays a role in the immunity acquired [13]. Many countries have moved from the use of plain DPT to the use of pentavalent vaccine. However, there is hardly any study that determined the effectiveness of pentavalent vaccine when compared to the DPT vaccine in terms of pertussis seroconversion/seroprotectation.

This study showed that the proportion of vaccines with protective anti pertussis antibody level was $33.9 \%$ for those that received plain DPT and $38.5 \%$ for those who took pentavalent vaccine. The seropositivity level for each of the vaccines obtained in this present study is far below the level of $80 \%$ necessary to achieve herd immunity [14], however there was no difference in the antibody response of children who received DPT when compared to those who received pentavalent. The seroprotection percentage of $38.5 \%$ obtained in this present study for children who received pentavalent vaccine is lower than that obtained by Hitt et al. [15] who had a seroprotection percentages of $49 \%$ vs $54 \%$ when pentavalent vaccine produced by two different manufacturer were compared. Following a booster dose of the vaccine, pertussis response increased to $79 \%$ vs $78 \%$. This finding emphasizes the need for pertussis vaccine booster in Nigeria. The finding of $38.5 \%$ in the present study also is very low compared to that obtained by Cepeding et al. [16] in Philippines who found $95.4 \%$ versus $97 \%$ when he evaluated non inferiority of two different pentavalent vaccines in terms of serconversion. The reason for the low level in our study area is not clear but could be due to certain genetic, immunologic reasons or vaccine failure. The above two studies did not compare DPT with pentavalent but rather compared two pentavalent vaccines. 
A study by Uket et al. [17] who compared DPT and pentavalent vaccines in this same environment in terms of tetanus antibody response had a good response of $93.9 \%$ and $96.5 \%$ respectively. This indicates that the present pentavalent vaccine in this environment induces good antibody response with tetanus antigen but low response with pertussis, and that more studies are needed to elucidate the reason(s) for this low antipertussis antibody response.

The present study showed that both at univariate and multivariate analysis level, vaccine type, age, sex and social class did not predict or affect the development of protective antibody level after 3 doses of DPT or pentavalent vaccine (Table 3) This finding is similar to observation made by Ozkal et al. [18] who observed no significant relationship between sex and Bordetella pertussis antibody level but in variant to the study by Ron et al. [19] who reported higher IgG antibody in males than females, however this study was carried out in adult and no explanation was given for this finding. A study by Duraoglu [20] in Ankara, observed no significant relationship between social class and Bordetella pertussis antibody levels similar to this present study. One would have expected otherwise with regards to low socioeconomic group considering the fact that this group is predisposed to overcrowding and repeated infection which can stimulate production of antibody.

This was a cross sectional study and unable to explore the rate of decay of pertussis antibodies especially beyond the age group studied.

\section{Conclusion}

This study showed no difference in the antipertussis antibody response between DPT and pentavalent vaccines, further study is required to determine the factors responsible for the low seroconversion/protection to Bordetella pertussis after vaccination.

Table 3. Univariate and multivariate analysis of possible predictors of protective antibody levels.

\begin{tabular}{cccccccc}
\hline & & \multicolumn{3}{c}{ Univariable Model } & \multicolumn{3}{c}{ Multivariable Model } \\
\cline { 3 - 7 } & & OR & $(95 \% \mathrm{CI})$ & $p$-value & OR & $(95 \% \mathrm{CI})$ & $p$-value \\
\hline \multirow{2}{*}{ Vaccine Type } & DPT & 1 & & & 1 & & \\
& Pentavalent & 1.22 & $0.82-1.82$ & 0.32 & 1.34 & $0.58-3.13$ & 0.49 \\
Male Sex & & 1.29 & $0.87-1.93$ & 0.21 & 1.31 & $0.87-1.97$ & 0.20 \\
Age (months) & & 1.0 & $0.99-1.02$ & 0.52 & 1.01 & $0.96-1.05$ & 0.78 \\
Social Class & 1 & 1.00 & & & 1.00 & & \\
& 2 & 1.39 & $0.66-2.90$ & 0.39 & 1.37 & $0.65-2.89$ & 0.40 \\
& 3 & 0.97 & $0.48-1.95$ & 0.94 & 0.97 & $0.48-1.96$ & 0.48 \\
& 4 & 0.61 & $0.28-1.30$ & 0.20 & 0.57 & $0.26-1.25$ & 0.26 \\
& 5 & 0.60 & $0.26-1.34$ & 0.21 & 0.57 & $0.25-1.30$ & 0.18 \\
\hline
\end{tabular}

Number of Observations $=422, \mathrm{AU}$ ROC $=0.60$. 


\section{Limitations of the Study}

1) Inability to know the efficacy of the vaccines that were administered to the study population.

2) This was a cross sectional study and unable to explore the rate of decay of pertussis antibodies.

3) Inability to diagnosed children who had natural pertussis infection.

\section{Acknowledgements}

Authors are grateful to the community leaders of the Akpabuyo L.G.A., Cross River State of Nigeria, for permission to carry out this study. Our gratitude also goes to the parents and children that participated in the study. We acknowledge the assistance of Dr. Udeme E. Ekrikpo with data analysis.

\section{Conflicts of Interest}

The authors declare no conflicts of interest regarding the publication of this paper.

\section{References}

[1] Tindade, E. and Skowronski, D. (2005) Epidemiology of Pertussis. Pediatric Infectious Disease Journal, 24, 810-818. https://doi.org/10.1097/01.inf.0000160708.43944.99

[2] Cherry, J.D. (2006) Epidemiology of Pertusssis. Pediatric Infectious Disease Journal, 25, 361-362. https://doi.org/10.1097/01.inf.0000210478.60841.69

[3] Edward, K. and Freeman, D.M. (2006) Adolescent and Adult Pertussis: Disease Burden and Prevention. Current Opinion Pediatrics, 18, 77-80.

[4] Banberger, E.S. and Srugo, I. (2008) What Is New in Pertussis. European Journal of Pediatrics, 167, 133-139. https://doi.org/10.1007/s00431-007-0548-2

[5] Matoo, S. and Cherry, J.D. (2005) Molecular Pathogenesis, Epidemiology and Clinical Manifestations of Respiratory Infection Due to Bodertella pertussis and Other Bordetella Species. Clinical Microbiology Reviews, 18, 26-82. https://doi.org/10.1128/CMR.18.2.326-382.2005

[6] Abdukarim, A.A., Ibrahim, R.M., Fawi, A.O., Adebayo, A.O. and Johnson, A.W. (2011) Vaccines and Immunization: The Past, Present and Future in Nigeria. Nigerian Journal of Paediatrics, 38, 186-194. https://doi.org/10.4314/njp.v38i4.72382

[7] Gavi (2012) Nigeria Launches Pentavalent Vaccine. Gavi Features News Library Gavi Alliance. https://www.gavi.org/news/media-room/nigeria-launches-pentavalent-vaccine

[8] Alexandre, P., Aparcida, S., Pietro, P., Celio, L.S., Guternberg, R., Ivo, L. and Osvalda, A. (2010) Antibody Response from Whole-Cell Pertussis Vaccine Immunized Brazillian Children against Different Strains of Bordetella pertussis. American Journal of Tropical Medicine and Hygiene, 4, 678-682. https://doi.org/10.4269/ajtmh.2010.09-0486

[9] Baler, J.D., Halperin, H., Edward, K., Deeker, M. and Stephens, D. (1992) Antibody Response to Bordetella pertussis Antigen after Immunization with American and Canadian Whole-Cell Vaccines. The Journal of Pediatrics, 121, 23-27.

https://doi.org/10.1016/S0022-3476(05)81138-2 
[10] Federal Republic of Nigeria Official Gazzette, Abuja, Cross River State (2009) National Population Commission Census 2006 Final Results. vol. 96, B1-42.

[11] Olusanya, O., Okpere, E. and Ezimokliai, M. (1985) Importance of Social Class in Voluntary Fertility Control in a Developing Country. West African Journal of Medicine, 4, 5-12.

[12] Bassey, G.E., Ekanem, E.E., Okpara, H.C. and Eyong, K.I. (2020) Pertussis Antibody Level in Preschool Nigerian Children. Journal of Pediatrics Infectious Diseases, 15, 11-15. https://doi.org/10.1055/s-0039-1693484

[13] Gergen, P.J., McQuillian, G.M., Kiely, M., Ezzati-Rice, T.M., Sutter, R.W. and Virella, G. (1995) A Population-Based Serologic Survey of Immunity to Tetanus in the United States. New England Journal of Medicine, 332, 761-766. https://doi.org/10.1056/NEJM199503233321201

[14] Ulefet, V., Nilay, G., Naci, O., Cemile, B., Serap, K. and Demet, K. (2005) Seroprevalance of Bordetella pertussis Antibodies among Healthy Adolescent Girls in Edrine. Swiss Medical Weekly, 135, 531-536.

[15] Hitt, S., Sangeeta, Y., Sanjay, L., Subliash, K., Suresh, J., Sameer, P., et al. (2013) Antibody Persistence of Two Pentavalent DTwP-HB-Hib Vaccine to Age of 15-18 Months and Response to the Booster Dose of Quadrilateral DTwP-Hib Vaccine. Vaccine, 31, 444-447. https://doi.org/10.1016/j.vaccine.2012.11.038

[16] Cepeding, M.R., Alberto, E., Versteilen, A., Ranscler, M., Bagchi, P. and De Palacio, P.L. (2016) Comparison of Immunogenicity and Safety of Pentavalent Vaccine Quivaxem in a Compact Prefilled Auto-Disabled (cPAD) Injection System versus Single-Dose Vials in Healthy Infant: A Phase 3 Open-Label, Randomized, Parallel-Group, Non-Inferiority Study. International Journal of Infectious Diseases, 46, 71-78. https://doi.org/10.1016/j.ijid.2016.02.015

[17] Uket, H.O., Ekanem, E.E., Okpara, H.C. and Ekrikpo, U.E. (2018) Comparative Tetanus Antibody Response of Nigerian Children to Diphtheria-Pertussis-Tetanus and Pentavalent Vaccines. Nigerian Postgraduate Medical Journal, 25, 137-142. https://doi.org/10.4103/npmj.npmj 4118

[18] Ozkal, A., Sensory, G., Acuner, C., Belet, N. and Guney, A.K. (2012) Seroprevalence of Bordetella pertussis Immunoglobulin G Antibodies among Children in Samsun, Turkey. Turkish Journal of Pediatrics, 54, 15-19.

[19] Rendi-Wagner, P., Tobia, J., Moerman, L., Goren, S., Green, M. and Cohen, D. (2010) The Seroepidemiology of Bordetella pertussis in Isreal-Estimate of Incidence of Infection. Vaccine, 28, 3285-3290.

[20] Duranogolo, C., Sonmez, C., Vurucu, S., Kesik, V. and Coplu, N. (2010) Evaluation of Pertussis Immunity Status in School Children Immunized with Whole Cell Vaccine. Epidemiology \& Infection, 138, 299-303.

https://doi.org/10.1017/S095026880999032X 


\section{Appendix I}

Questionnaire

Please answer the following question correctly. They will be use for medical research only and will be treated with confidentiality .

Serial No

Date.

\section{SECTION 1}

\section{DEMOGRAPHIC INFORMATION}

1) NAME:

2) Date of birth/date at last birthday.

3) Sex of the child:

a) Male

b) Female $\square$

4) Tribe: Annang $\square$ Efik $\square$ Ibibio $\square$ Ejagham $\square$ Others (specify)

5) Nationality: Nigerian $\square$ Cameroon $\square$ others (specify)

6) How long have you been resident in Akpabuyo LGA (in years)....

7) Number of children in the family...

8) Total number of children in the household.

9) Birth order of subject.

10) Father's occupation: Civil servant $\square$ farming $\square$ Trading $\square$ Artisan Others (specify)

11) Mother's occupation: Civil servant $\square$ Farming $\square$ Trading $\square$ Artisan others (specify)

12) Highest education level attended by father (pls tick one)

University $\square$ Secondary school $\square$ Primary school $\square$ None

13. Highest education level attended by mother

University $\square$ Secondary School $\square$ Primary School $\square$ None

14) Immunization card sighted Yes $\square$ No $\square$

15) Date of immunization

DPT1...

DPT2.

DPT3....

Section II (TO BE COMPLETED BY THE INVESTIGATOR PLEASE

16) Social class

17) Blood analysis

a) Total $1 \mathrm{gG}$ antibody.

\section{Appendix II}

Scoring indices for social class determination.

\begin{tabular}{|c|c|}
\hline Father's Occupation & Mother's Occupation \\
\hline Score 1 & Score 0 \\
\hline $\begin{array}{l}\text { Professional, top civil servant, Politician, } \\
\text { businessman }\end{array}$ & Education to University Level \\
\hline Score 2 & Score 1 \\
\hline $\begin{array}{l}\text { Middle class bureaucrats, technician, Skilled } \\
\text { artisans, well-to-do traders. }\end{array}$ & $\begin{array}{l}\text { Secondary or tertiary below the University } \\
\text { example, college Of education, school of nursing }\end{array}$ \\
\hline
\end{tabular}




\section{Continued}

\begin{tabular}{ll}
\hline Score 3 & Score 2 \\
Unskilled workers and those in general. & No school or schooling up to primary level only. \\
Whose income is below minimum wage &
\end{tabular}

\section{Appendix III}

\section{Stratification of the social class of the study population}

\begin{tabular}{cc}
\hline Social class & Total score \\
\hline Social class I & 1 \\
Social class II & 2 \\
Social class III & 3 \\
Social class IV & 4 \\
Social class V & 5 \\
\hline
\end{tabular}

\section{Cover Note}

1) DPT written in full in the title.

2) Study time and site is included in the methods and subject part of the abstract.

3) The authors are not aware of anyone that has done a similar study in their locality.

4) The social class was defined using Olusanya's classification as provided in Appendix II.

5) Questionnaire has been provided in Appendix I

6) Sociodemographic characteristics in Table 1.

7) Table 2 referenced in the main text.

8) Limitation of the study stated.

9) The low seroconversion/protection to Bordetella pertussis is not about pentavalent vaccine because those who took DPT still had low seroconversion. Further study is needed to determine the factors responsible for this observation because similar study done by Uket et al. showed good response.

10) Mistakes checked

11) The similarity has been sorted out. 